\title{
ORIENTATIONS OF CRYSTALLOGRAPHIC AXES IN SKELETAL ELEMENTS OF ORDOVICIAN CRINOIDS
}

BODENBENDER*, Brian E. and AUSICH, William I., Department of Geological Sciences, Ohio State University, 130 Orton Hall, 155 South Oval Mall, Columbus, OH 43210-1397, U.S.A.

Homologies among skeletal elements of Paleozoic crinoids are under debate. Crinoid skeletal elements, like those of all echinoderms, approximate single crystals of calcite and have $c$ and $a$ crystallographic axes. We examined the orientations of $c$ axes to assess their utility as structural indicators of homologies in crinoids.

Although crinoids have continually modified their calyx architecture over time, many of the major crinoid body plans arose early in the clade's history. We examined skeletal crystallography of calyx plates in 10 Ordovician crinoids in order to establish initial patterns of crystallographic axis orientations among the major crinoid taxa, prior to possible subsequent evolutionary modification. Specimens included representatives of the monobathrid and diplobathrid camerates, cladids, and disparids. We used calcite decoration and optical goniometry to determine the orientations of crystallographic axes in individual skeletal elements without disarticulating or thin-sectioning specimens.

Ordovician crinoids display broad similarities in the orientations of $c$ axes across all groups examined. Most plates' $c$ axes lie within the vertical radial plane that passes through the oralaboral axis and bisects the plate. The major plates at the base of the calyx have $c$ axes that are approximately normal to the plate surface, although smaller plates higher on the calyx can have $c$ axes that are more nearly parallel to the plate surface. The first secundibrachs, at the bases of arm branches, are exceptions to the typical radial distribution of $c$ axes, having $c$ axes that diverge laterally by more than $30^{\circ}$ from the radial plane that bisects the arm. More distal arm plates, however, have axes that again align more closely with the radial plane bisecting the arm.

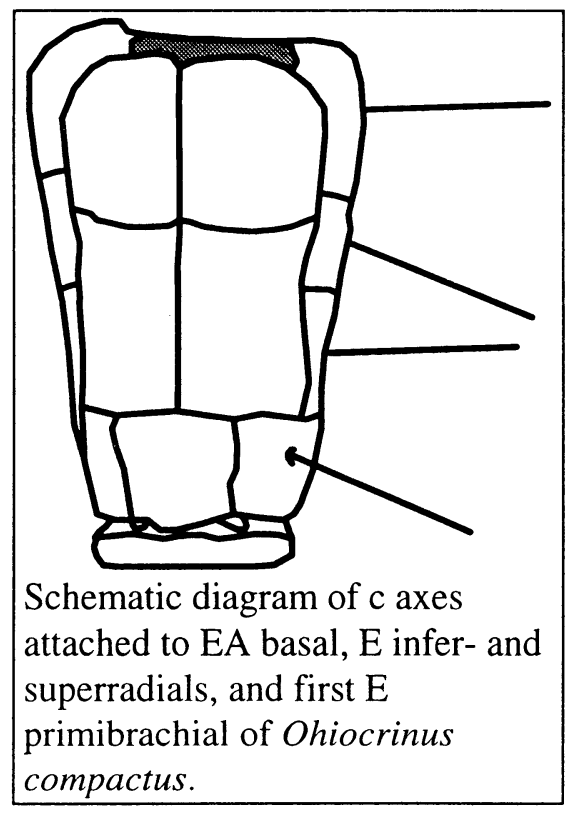

The small sample examined to date suggests that establishment of the orientations of crystallographic axes during skeletal development is evolutionarily conservative in crinoids. That is, even though species differ in the number and placement of major calyx plates, these plates show similar crystallographic patterns. The orientation of $c$ axes within radial planes in crinoids duplicates the pattern in major thecal plates of blastoids and echinoids, suggesting a fundamental similarity in the establishment of skeletal plate orientations during development in these groups.

The similarity in axis orientations among the crinoids surveyed suggests that $c$ axes may not in general indicate homologies throughout the crinoids. This does not rule out skeletal crystallography as an indicator of skeletal plate homologies in particular cases, nor does it rule out $a$ axes as potential indicators of homology. 